\title{
Simulation analysis of cooling methods of an on-board organic Rankine cycle exhaust heat recovery system
}

\author{
Meng Zhao ${ }^{1}$, Fei Xu' ${ }^{2}$, Mingshan Wei ${ }^{1, *}$, Guohong Tian ${ }^{3}$, Hong Zhang ${ }^{1}$
}

1 School of Mechanical Engineering, Beijing Institute of Technology, Beijing 100081, China

2. Department of Electrical Engineering, Tsinghua University, Beijing 100084, China

3. Department of Mechanical Engineering Sciences, University of Surrey, Guildford, GU2 7HX, UK

\section{(*) Corresponding Author:}

Prof. Dr. Mingshan Wei

Address: School of Mechanical Engineering, Beijing Institute of Technology,

No.5 South Zhongguancun Street, Haidian, Beijing 100081, China

Tel: +861068911373

Fax: +861068912519

E-mail: mswei@bit.edu.cn

\section{Novelty statement}

- Performance of an on-board ORC exhaust heat recovery system using water or air cooling method was evaluated.

- Relation of benefit and penalty of the ORC system with cooling system was analyzed.

- Performance evaluation of the engine with ORC system at different engine operating conditions and ambient temperatures was presented. 


\section{Summary}

Energy saving and emission reduction of engines were taken seriously, especially for vehicular diesel engines. Exhaust heat recovery based on organic Rankine cycle (ORC) system has been considered as an effective approach for improving engine fuel economy. This article presents the investigation of water or air cooling method for an ORC exhaust heat recovery system on a heavy duty truck through simulations. The models of the truck engine and the ORC system were developed in GT-suite, and the integration system model was developed in the Simulink environment. The validity of the models was verified experimentally. The performance of the vehicular engine with ORC system using water or air cooling method was comparatively analyzed. The simulation results indicated that water cooling method is more suitable for the vehicular ORC system than air cooling method. The relation between benefit and penalty of the ORC system and cooling system was discussed. The operating condition of the cooling system was confirmed having significant effects on the combined system performance, especially the fan speed. The performance improvement of the engine with the use of ORC system was further evaluated under different engine operating conditions and ambient temperatures. Lower ambient temperature had positive impacts on the engine fuel economy. The mass flow rate of exhaust gas for heat recovery should be regulated for better performance under high ambient temperature.

Key words: Heavy-duty truck, Diesel engine, ORC, Cooling method, Operating condition, Ambient temperature, BSFC

\section{Introduction}

The energy saving and emission reduction of the internal combustion engines have received more attention. New vehicular emission regulations has been introduced in 2014 [1], and the regulations have been implemented for light duty diesel vehicles at ambient temperature of 293-303K [2]. The thermal efficiency of engines is about $40 \%$ [3]. Approximately $30 \%$ of the energy input from fuel is contained in the exhaust gas [4], and the rest of 
heat energy is released through intake air intercooling and engine coolant. Recovering the exhaust heat is an effective method for achieving the reduction in fuel consumption and emissions [5]. Thermoelectric device [6, 7] and turbo-compounding $[8,9]$ have been applied to recover exhaust heat from engines. The ORC system has been considered as an efficient method for waste heat recovery. Various ORC systems have been investigated by many researchers. Simple ORC system [10], regenerative ORC systems [11, 12], preheated ORC systems $[13,14]$ and double ORC systems $[15,16]$ have been presented in previous publications. Several scholars have researched the expander $[17,18]$ and the pump $[19,20]$ in ORC systems. Heat exchanger [21, 22] and working fluid [23, 24] which have significant effects on performance of ORC systems have also been studied. Moreover, the system cooling problem limit the development of the applications of ORC system on vehicles.

A few scholars have discussed the cooling demand of ORC systems. Zhang et al. [25] analyzed the performance of an ORC exhaust gas heat recovery system which used an air cooled condenser. Neto et al. [26] discussed two water cooling types of an ORC system for waste heat recovery from engines. Yang et al. [27] optimized and analyzed the performance of an ORC for recovering cylinder jacket water heat from a marine engine, and discussed the effects of the inlet temperature of the cylinder jacket water and the cooling water on the system performance. Ge et al. [28] adopted an air cooled condenser for cooling the ORC system which was utilized to recover low grade waste heat. Carcasci et al. [29] also analyzed the performance of an ORC system with an air cooled condenser for recovering exhaust heat from gas turbine. Shi et al. [30] designed an exhaust gas mixture recirculation loop to stabilize the exhaust gas heat source. The working fluid in the condenser was directly cooled by air. Grelet et al. [31] assessed the performance of the ORC system which was cooled by the engine coolant system or a separate cooling system under different driving cycles. Lion et al. [32] also presented the two water cooling method for an ORC system which was used to recover waste heat from a commercial agricultural tractor engine. Air and water cooling method for ORC systems were explored. However, the 
difference of the two cooling mode for the on-road exhaust heat recovery system requires further analysis.

The applications of ORC system in the transportation sector have been researched. The positive and negative effects of ORC waste heat recovery systems on performance of engines and vehicles were explored. Domingues et al. [33] evaluated the exhaust waste heat recovery potential of a RC system for vehicle engine. Performance of the RC system with Water, R123 and R245fa under different evaporation pressure was compared. Zhao et al. [34] evaluated the performance of a diesel engine with ORC system, and discussed the effects of the ORC system on the acceleration performance of the engine. Chen et al. [35] developed a confluent cascade expansion ORC system to recover engines waste heat. The system performance was evaluated under different engine operating conditions. The results indicated that the peak thermal efficiency of the engine can be improved from $45.3 \%$ to $49.5 \%$. Horst et al. [36] predicted the performance of an ORC waste heat recovery system on a passenger car. The results showed that the ORC system could improve fuel economy by $3.4 \%$, but the negative interactions reduced the fuel saving potential by 60\%. Dolz et al. [37] and Battista et al. [38] also analyzed the integration performance of engines with ORC systems. The effects of the increased weight and exhaust backpressure caused by the ORC system on the performance of the engine were discussed. Usman et al. [39] studied the effects of an ORC system on the performance of a light duty vehicle. The results showed that the maximum power improvement is $5.82 \%$ at the vehicle velocity of $100 \mathrm{~km} / \mathrm{h}$. The ORC system was not beneficial when the vehicle ran with a speed lower than $48 \mathrm{~km} / \mathrm{h}$. Moreover, Capata et al. [40] evaluated the feasibility of an "on-board" ORC system and analyzed the performance of the ORC system. While the cooling demand for the on-board ORC systems should be further analyzed.

Through investigation, it is found that the performance evaluation of ORC waste heat recovery systems which were applied on vehicles has been presented. However, there is no available literatures focus on comparing the cooling methods of the on-board exhaust heat recovery system for heavy-duty truck engines. In this paper, both 
water and air cooling method for the ORC system were discussed. The cooling system for the ORC system was separate with the engine cooling system. The performance of an on-board ORC exhaust heat recovery system for heavy duty truck was evaluated through simulations. The models of the engine with the truck, the ORC system and the cooling system were developed in GT-suite. The combined system model was developed in the Simulink environment. The performance of the engine with ORC system cooled by either water or air was comparatively analyzed. The relation between power output and power consumption of the ORC system and the cooling system was analyzed, and the benefit of the system was discussed. The performance improvement of the combined system was further evaluated at different engine operating conditions. The effects of ambient temperature on the combined system performance improvement were also analyzed.

\section{System configuration}

An ORC system using either air or water cooling method was developed to recover exhaust waste heat from a diesel engine propelling a heavy duty truck as shown in Figure 1. The engine integrated with the ORC system by an evaporator. Valves ' $a$ ' and ' $b$ ' in Figure 1 are proportional exhaust bypass valves which are used to adjust the mass flow rate of the exhaust gas entering the evaporator. Figure 1(A) shows the ORC system with an aircooled condenser. Figure 1(B) describes the ORC system with a water cooled condenser in a water cooling system which is isolated from the engine cooling system. 


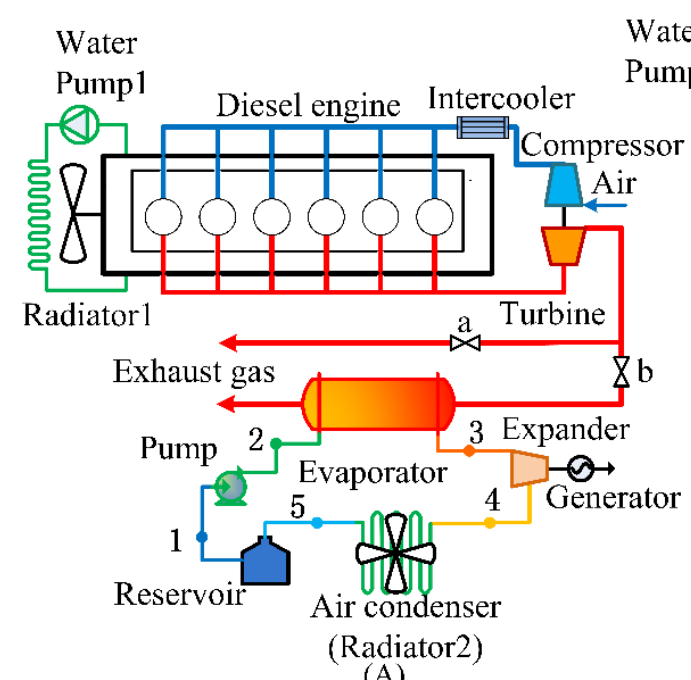

(A)

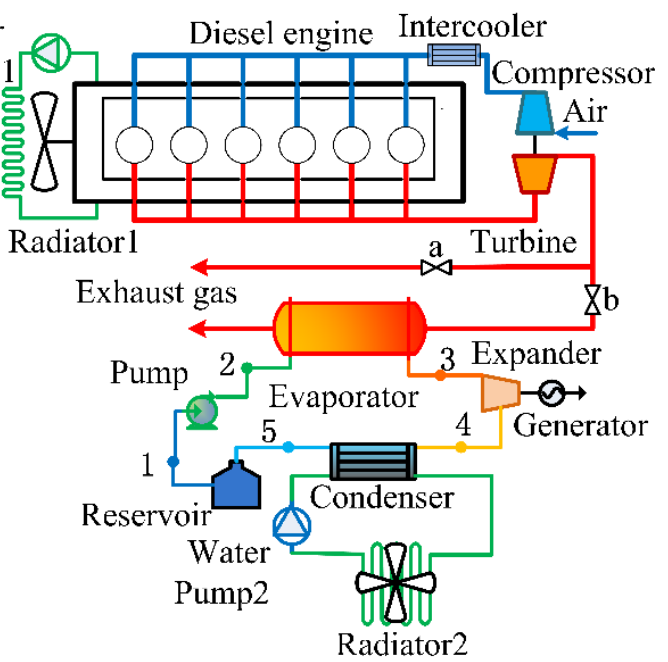

(B)

Figure 1 Schematic diagram of the combined system. (A): The ORC system using air cooling method, and (B): The ORC system using water cooling method

\subsection{Performance of the base engine}

The base engine is a six-cylinder four-stroke turbocharged diesel engine for heavy duty applications. The truck has a ten-speed manual transmission. Table 1 presents the specifications of the truck and engine.

Table 1 Specifications of the heavy-duty truck engine

\begin{tabular}{lll}
\hline Items & Parameter & Value \\
\hline \multirow{5}{*}{ Engine } & Rated power $/ \mathrm{kW}$ & 258 \\
& Rated speed $/ \mathrm{r} \cdot \mathrm{min}^{-1}$ & 2100 \\
& Speed under the Maximum torque condition $/ \mathrm{r} \cdot \mathrm{min}^{-1}$ & $1300 \sim 1600$ \\
& Displacement/L & 8.6 \\
& Stroke and cylinder bore/mm & $112 \times 145$ \\
& Compression ratio & 17.5 \\
& Vehicle mass $/ \mathrm{kg}$ & 9800 \\
& Rated load $/ \mathrm{kg}$ & 17135 \\
Truck & Drive model & $8 \times 4$ \\
& Tire number & 12 \\
& Highest speed $/ \mathrm{km} \cdot \mathrm{h}^{-1}$ & 95 \\
\hline
\end{tabular}

Engine performance was evaluated experimentally [34]. The maximum mass flow rate and temperature of the exhaust gas can reach to $0.417 \mathrm{~kg} / \mathrm{s}$ and $754 \mathrm{~K}$ respectively. The enthalpy and entropy of the exhaust gas at different temperature and pressure were obtained based on REFPROP. The exhaust energy and exergy were calculated by Eq. (1) and (2) respectively. The energy input rate from fuel, the energy and the exergy flow 
rate of exhaust gas at different engine operating conditions are shown in Figure 2. The exhaust energy and exergy can reach up to $372 \mathrm{~kW}$ and $74 \mathrm{~kW}$ when the ambient conditions are $T=298.15 \mathrm{~K}$ and $p=99.5 \mathrm{kPa}$. The exhaust energy and exergy indicate the potential of the ORC exhaust waste heat recovery system.

Energy flow rate of the exhaust gas:

$$
\dot{Q}_{\mathrm{exh}}=\dot{m}_{\mathrm{exh}} h_{\mathrm{exh}}
$$

Exergy of the exhaust gas:

$$
\dot{E}=\dot{m}_{\text {exh }}\left[\left(h_{\text {exh }}-h_{\text {amb }}\right)-T_{\text {amb }}\left(s_{\text {exh }}-S_{\text {amb }}\right)\right]
$$

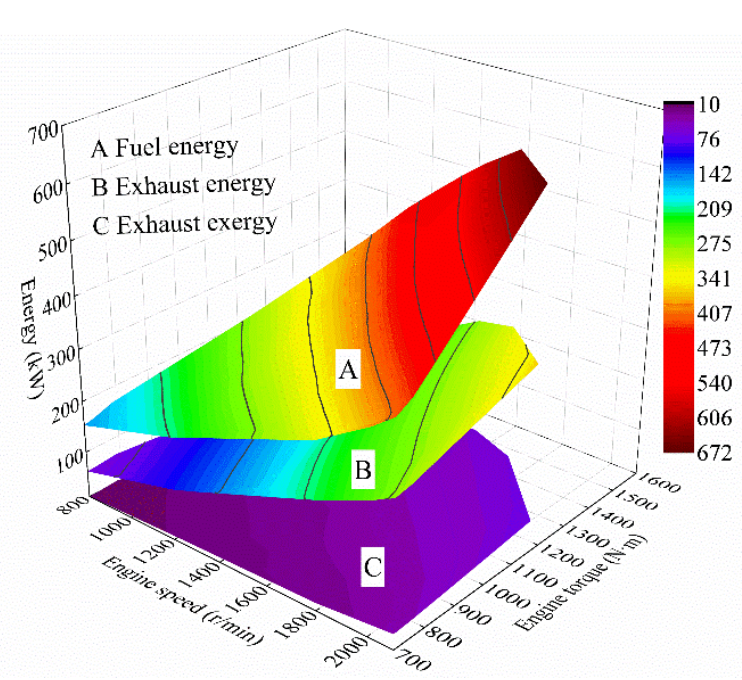

Figure 2 Energies of the diesel engine at different engine operating conditions

\subsection{Specifications of the ORC system}

In the running process of the ORC system, the liquid working fluid is pressurized from the reservoir into the evaporator using an externally powered pump. The exhaust gas flows through the valve ' $b$ ' into the evaporator and heats the liquid working fluid into high temperature vapor. The working fluid vapor flows through the expander which converts thermal energy into mechanical power. Subsequently, the working fluid is condensed into liquid in the condenser and flows into the reservoir. Then, the liquid working fluid is pumped again to form a cycle.

In this study, R245fa was selected as the system working fluid due to its environmental, safety and thermo- 
physical features. The water cooled ORC system consisted of a shell and tube evaporator, a plate condenser, a diaphragm metering pump, a scroll expander with a generator and a reservoir. An additional cooling system that cools the ORC system consisted of a finned tube radiator, an electronic mechanical fan and a water pump. 50\% (v/v) ethylene glycol was used as the cooling liquid in the water cooling system. The air cooled ORC system consisted of an air-cooled finned tube condenser which had the same parameters of the radiator for the separate cooling system. The fan and the water pump consumed power which was supplied externally.

\section{System modeling}

\subsection{Models development}

The performance of the engine with ORC system was evaluated through simulations. The model of the diesel engine with the truck was built in GT-suite environment. The engine model consisted all the important components such as the intake and exhaust valves, the turbocharger and the fuel injectors. The main parameters are described in Table 1. The Chen-Flynn friction model and a three term Wiebe function were selected in the engine model. The truck model consisted the vehicle body, the clutch, the transmission and tires. The vehicle weight, the transmission parameters and the tire parameters of the truck, the fuel injection quantity and speed of the engine were set in the model. The ambient pressure and temperature was set as $99.5 \mathrm{kPa}$ and $298.15 \mathrm{~K}$ [41].

The ORC system models were also developed in GT-suite [42]. Shell and tube and plate heat exchanger models were used to simulate the evaporator and the condenser in the ORC system. A tube fin heat exchange model was used to simulate the radiator of the cooling system. Simple models of positive displacement pump and expander were selected in the GT-suite libraries to simulate the working fluid pump, the water pump and the expander of the ORC system. The displacements were $10 \mathrm{~cm}^{3}, 50 \mathrm{~cm}^{3}$ and $106 \mathrm{~cm}^{3}$, respectively. The volumetric efficiencies and isentropic efficiencies of the pumps and expander models were 1 and 0.65 [42-44]. 
The fluid volumetric flow rate and the enthalpy change across the pumps and the expander were calculated with the constant displacement, volumetric efficiency and isentropic efficiency in the GT-suite model. The external air velocity of the radiator in the water cooled ORC system and the air condenser in the air cooled ORC system was equal to the truck speed. The cooling fan of the cooling system is a map based model, and the behavior of the fan was defined based on measured performance data. The heat transfer areas of the evaporator, the condenser and the radiator were $4.31 \mathrm{~m}^{2}, 11.2 \mathrm{~m}^{2}$ and $9.61 \mathrm{~m}^{2}$, respectively. The total refrigerant charge of the ORC system was set as $35 \mathrm{~L}$. In the GT-suite model, the ORC operating condition was mainly controlled by both the expander speed and the pump speed. The operating condition of the added cooling system was adjusted by the speeds of the fan and the water pump.

A bridging model was developed in the Simulink environment which allowed dynamic data transfer between the truck/engine model and the ORC system model, depicted in Figure 3. The exhaust temperature and mass flow rate were calculated by the engine model and transferred to the ORC model. The exhaust gas pressure at point ' 6 ' was calculated in the ORC model and transferred back to the diesel model as the backpressure. The truck speed was transferred to the ORC model as the face velocity of the air-cooled condenser. The bridging model needed to be solved iteratively due to the dependence of the temperature, mass flow rate of the exhaust gas and the engine backpressure. The data were transferred with high level of precision between the models in a time step of $0.01 \mathrm{~s}$. This allowed the combined model to accurately evaluate the performance of the combined system at different operating condition and ambient temperature. 
Truck/Engine GT-suite model

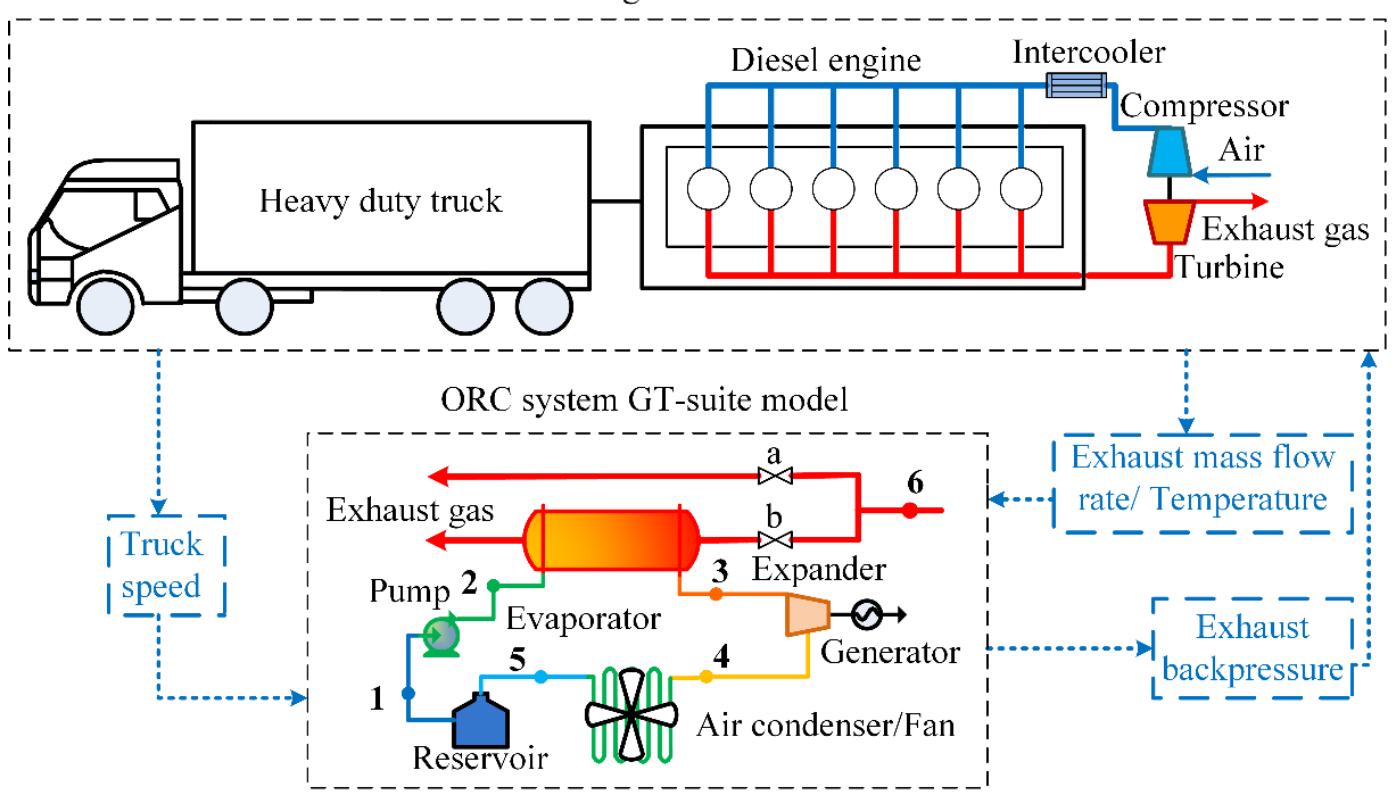

Figure 3 Simulation model of the engine with ORC system cooled by air

The performance of the engine integrated with the ORC system cooled by different liquids was evaluated.

The backpressure change, the net power output change, the BSFC reduction of the combined system and the

ORC system thermal efficiency were discussed.

Backpressure change of the engine with ORC system is:

$$
\Delta P=P_{\text {ew }}-P_{\text {ewo }}
$$

Net power output change of the engine with water cooled ORC system is calculated as:

$$
\dot{W}_{\mathrm{n}}=\dot{W}_{\mathrm{ew}}+\dot{W}_{\mathrm{exp}}-\dot{W}_{\mathrm{pu}}-\dot{W}_{\mathrm{f}}-\dot{W}_{\mathrm{wp}}-\dot{W}_{\mathrm{ewo}}
$$

Net power output change of the engine with air cooled ORC system is defined as:

$$
\dot{W}_{\mathrm{n}}=\dot{W}_{\mathrm{ew}}+\dot{W}_{\mathrm{exp}}-\dot{W}_{\mathrm{pu}}-\dot{W}_{\mathrm{f}}-\dot{W}_{\text {ewo }}
$$

BSFC reduction of the engine with ORC system is defined as:

$$
\triangle B S F C=\frac{\dot{m}_{\mathrm{fu}}}{\dot{W}_{\mathrm{ewo}}}-\frac{\dot{m}_{\mathrm{fu}}}{\dot{W}_{\mathrm{ewo}}+\dot{W}_{\mathrm{n}}}
$$

Thermal efficiency of the ORC system is calculated as:

$$
\eta_{\mathrm{ORC}}=\frac{\dot{W}_{\mathrm{exp}}-\dot{W}_{\mathrm{pu}}}{\dot{Q}_{\mathrm{eva}}}
$$




\subsection{Model validation}

The GT-suite models of the engine and the ORC system were validated against experimental results to verify the computational accuracy. The performance of the radiator ('Radiator2' as shown in Figure 1) with water instead of working fluids or ethylene glycol was analyzed experimentally. The validation results of air and water outlet temperature for the radiator model in the water cooling system were presented in Figure 4 (A). The results indicated that the air cooled radiator model has high accuracy. Furthermore, the experimental evaluation and performance analysis of a water cooled ORC system which was used to recover heat from medium temperature exhaust gas have been introduced in Ref. [45]. The temperature of working fluid at the condenser outlet was measured at different operating conditions, and the comparison results between experiments and simulations are shown in Figure 4 (B). The validation results indicate that the water cooled condenser model built in GTsuite has small errors. The validation of the engine model has been presented in Ref [34]. The results of comparison show that the maximum error is lower than $2.5 \%$. This suggests that the GT-suite models have high accuracy and can be used for performance investigation of the combined system.

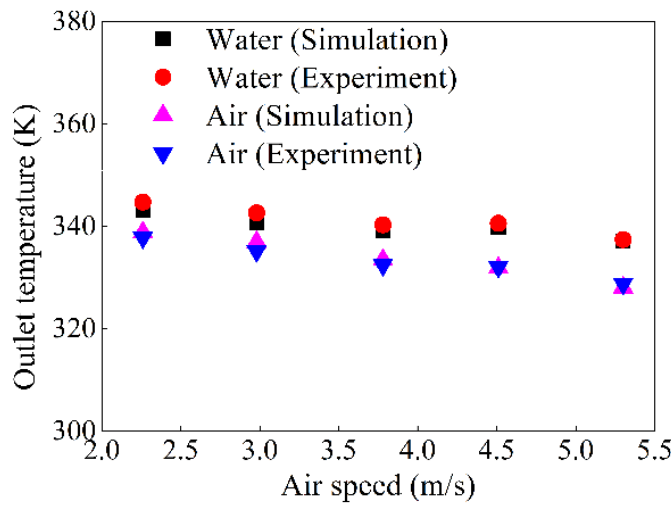

(A)

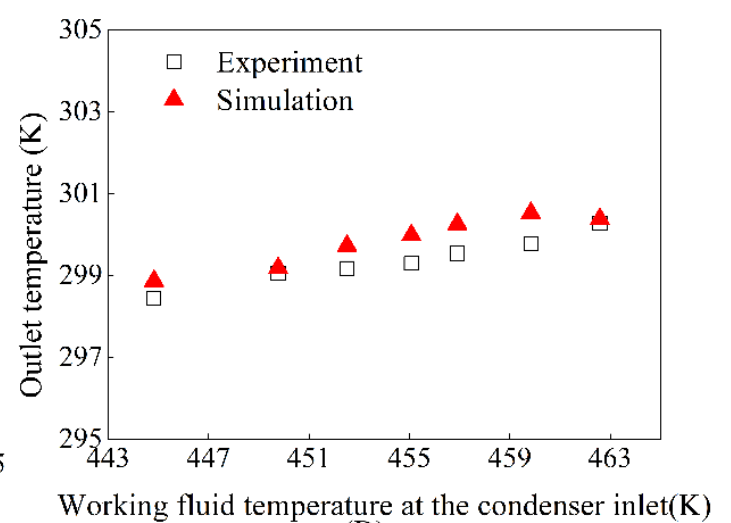

(B)

Figure 4 Validation of models. (A): Air and water outlet temperature of the radiator, and (B): Temperature of working fluid at the condenser outlet

\section{Results and discussion}

In this section, the performance of the engine with ORC system using water and air cooling method was comparatively analyzed. Besides, the power benefit of the ORC system at different cooling system operating 
conditions was discussed. The performance of the engine with ORC system at different engine operating conditions was evaluated. At last, the effects of ambient temperature on the system performance improvement were also analyzed.

\subsection{Performance evaluation of the engine with ORC system using different cooling method}

The steady performance of the diesel engine with ORC system using water or air cooling method was analyzed. The engine was operated with different speeds and full loads. The truck transmission was set at the highest gear. The operating condition of the ORC system and the cooling system was steady. Valve 'a' was fully closed and the valve ' $b$ ' was fully opened. The effects of the cooling method on the performance of the combined system are discussed in this section.

Figure 5 shows the respective performance of the combined system. The net power output increment of the engine with ORC system at different engine speeds was compared as shown in Figure 5(A). The water cooled system had higher net power output improvement. The improvement of power output increases with the increasing of engine speed for the two ORC systems. The difference of power output improvement between the two systems is minimum at engine speed of $2100 \mathrm{r} / \mathrm{min}$, and the maximum difference is $1.23 \mathrm{~kW}$ at engine speed of $1500 \mathrm{r} / \mathrm{min}$. The relations of power output and consumption for the two ORC systems when the engine operates at the engine rated operating condition of $2100 \mathrm{r} / \mathrm{min}$ and $1168 \mathrm{~N} \cdot \mathrm{m}$ were analyzed in detail as shown in Figure 5(B). The output power of the water and air cooled ORC system is $5.47 \mathrm{~kW}$ and $4.51 \mathrm{~kW}$ respectively. Because the working fluid has lower condensation temperature and pressure for the water cooled ORC system according to Figure 5(C). Both the expansion ratio and power output of the system are higher. Furthermore, the power consumption of the fan for the two case is similar, as well the water pump has low power consumption, so the power consumption of the cooling systems has small difference which is about $0.1 \mathrm{~kW}$. Results show that the power output improvement of the water and air cooled system is $3.9 \mathrm{~kW}$ and $3.03 \mathrm{~kW}$ at the engine power 
output of $258 \mathrm{~kW}$.

Figure 5(C) presents the condensation pressure of the working fluid. The condensation pressure of the working fluid increases with the increasing of engine speed, due to the increasing of exhaust energy and the limited cooling capacity of the cooling system. Water has higher specific heat and heat transfer efficiency than air, so the working fluid has lower condensation pressure for the water cooled ORC system, while the difference between the two systems decreases with engine speed. Figure 5(D) shows the ORC system thermal efficiency. The water cooled ORC system has higher thermal efficiency than the air cooled ORC system. The maximum thermal efficiency of the water cooled ORC system is $6.8 \%$ at engine speed of $1500 \mathrm{r} / \mathrm{min}$. The analysis results indicate that the engine with the water cooled ORC system has better power performance. Therefore, the onboard ORC system used water cooling method for the following investigations.
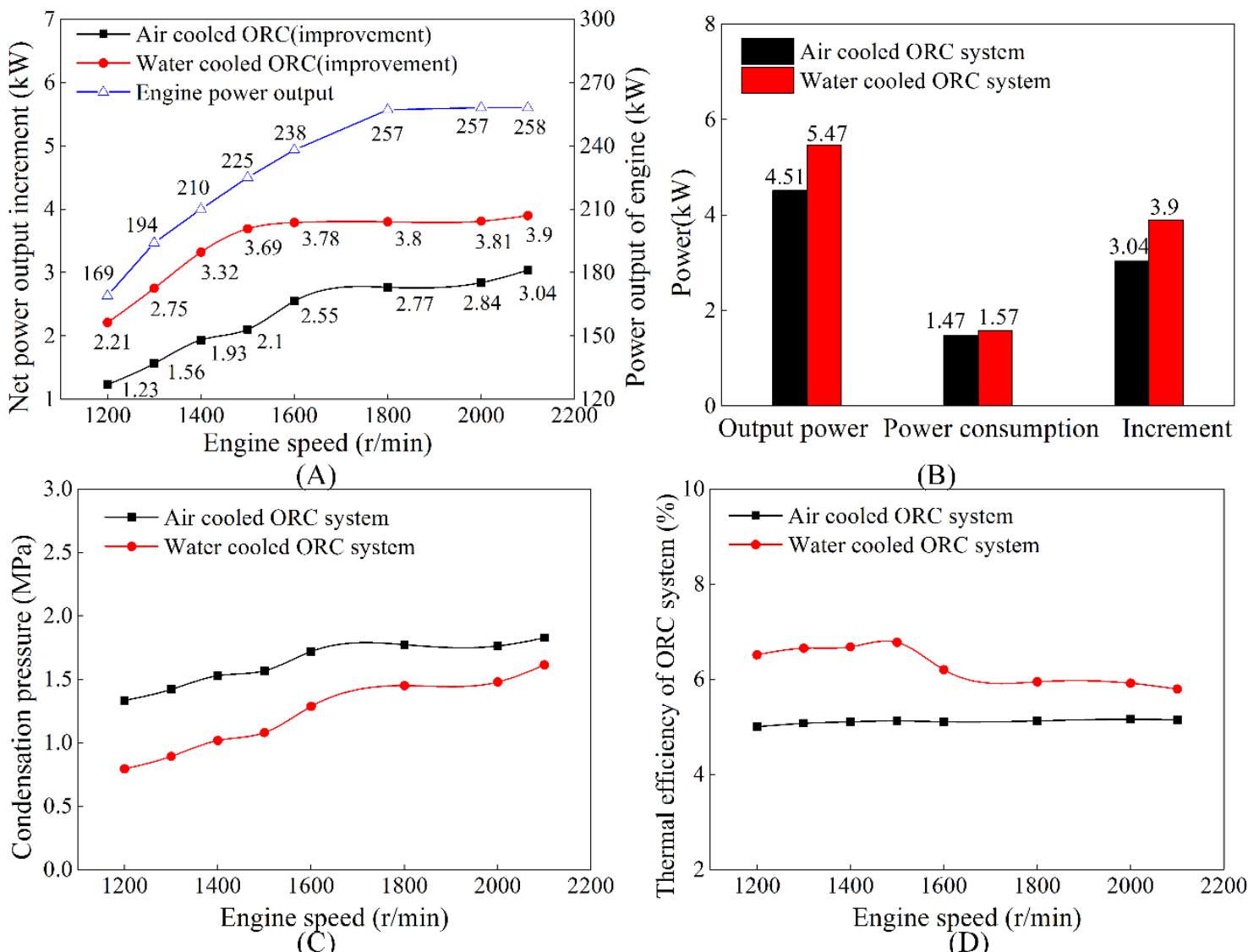

Figure 5 Performance of the engine with the air or water cooled ORC system. (A) Power output change, (B) Relation of power output and consumption, (C) Condensation pressure of working fluid, and (D) Thermal efficiency of the ORC 
system

\subsection{Power benefit of the ORC system using water cooling method}

The increase of power consumption of the cooling system with the increasing condenser heat rejection has been presented in Ref. [36]. Evaporation pressure and condensation pressure have significant impacts on the performance of ORC systems [46]. The effects of the cooling system on performance of the ORC system were discussed. The relation between the benefits and penalties of the ORC system and the cooling system was analyzed.

The engine was operated at $1200 \mathrm{r} / \mathrm{min}$ with full engine load, and the truck speed was $54.3 \mathrm{~km} / \mathrm{h}$. All exhaust gas passes through the evaporator, i.e. valve 'a' was fully closed. The mass flow rate of cooling air was measured at the air-condenser outlet. The ORC system output power and the power consumption of the cooling system at different operating conditions of the cooling system were presented in Figure 6. Increasing the mass flow rate of the cooling liquid and cooling air increases the heat transfer in the condenser and decreases the condensation pressure of the working fluid. Both the pressure ratio of the expander and the ORC system output power increased accordingly. However, the power consumption of the fan and the water pump also increased. The cooling system power consumption is higher than the ORC system output power when the cooling air mass flow rate is greater than $1.88 \mathrm{~kg} / \mathrm{s}$ at fan speed of $3750 \mathrm{r} / \mathrm{min}$, at which point the ORC system produced no benefit. Therefore, the cooling system operating condition has significant effects on the system power performance. The selection of a suitable operating condition can effectively improve the ORC system power output and reduce the cooling system power consumption. 


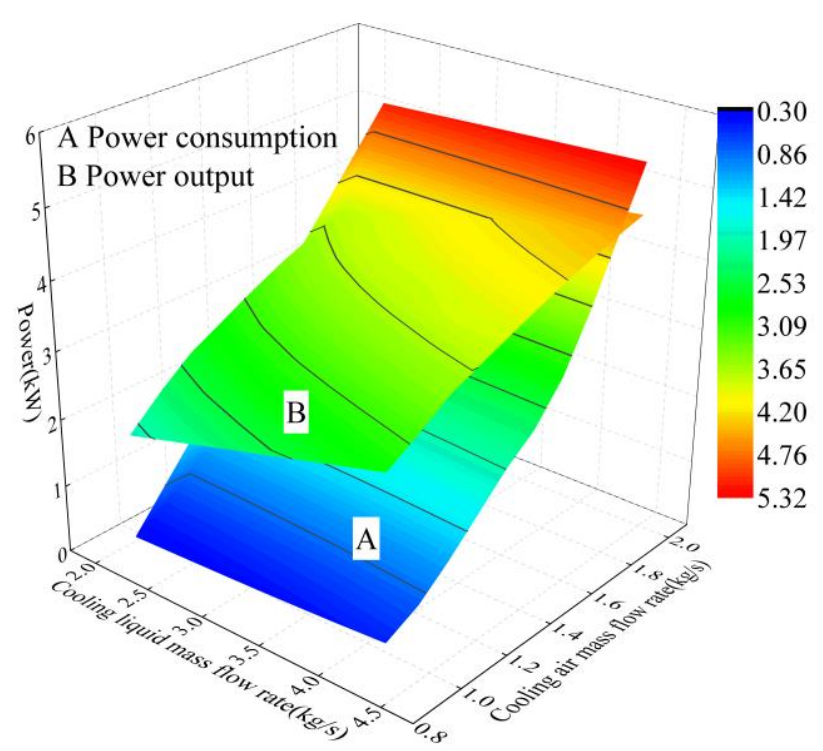

Figure 6 Variations of the ORC system power output and power consumption of the cooling system

The performance of the combined system with different engine speed at full load conditions was further evaluated. The effects of the fan speed on the combined system output power improvement were presented in Figure 7. Below engine speed of $1300 \mathrm{r} / \mathrm{min}$, increasing fan speed in general had negative effects on the net power output. This because the exhaust heat was relatively low therefore the cooling capacity with lower fan speed was adequate. As the engine speed increased, it was beneficial to provide additional cooling by the fan and the net power output increased with increasing fan speed. However at a certain fan speed of approximately $3200 \mathrm{r} / \mathrm{min}$, the benefit was overcome by the power consumed by driving the fan. Therefore, the net power output started to decline above the optimal fan speed. At high engine speed above $2000 \mathrm{r} / \mathrm{min}$, however, it appeared that the impact of fan speed became insignificant because the large amount of heat contained in the exhaust gas can always meet the power consumption requested by driving the fan. In general, optimal fan speeds exist at different engine conditions to allow the highest power output from the ORC system. 


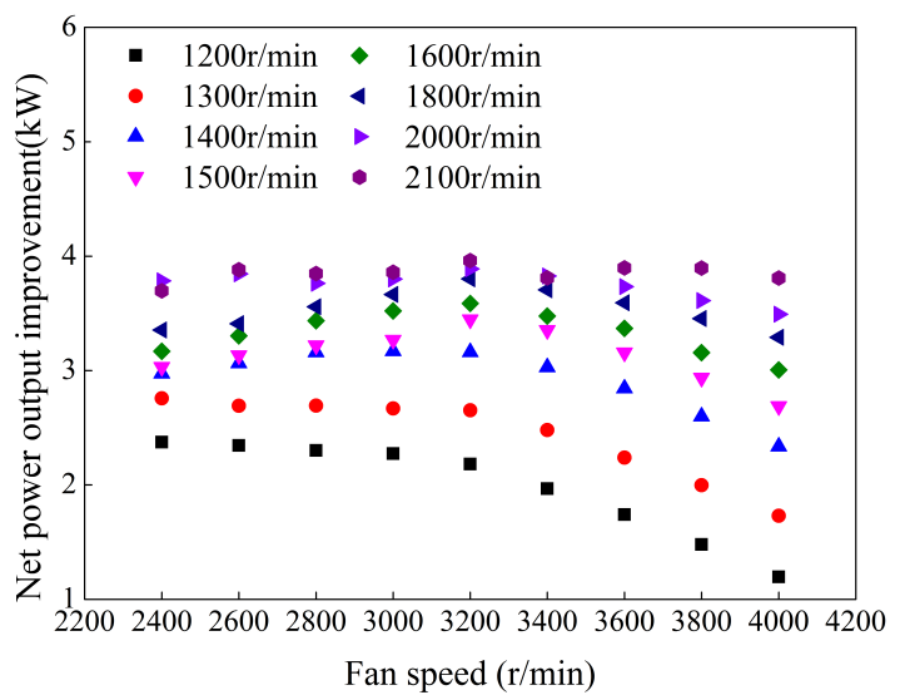

Figure 7 Power output improvement of the combined system at different engine speed

\subsection{Performance evaluation at different engine operating condition}

Based on the above analysis, the operating condition of the cooling system was set. The fan speed and the water pump speed of the cooling system was $3200 \mathrm{r} / \mathrm{min}$ and $2500 \mathrm{r} / \mathrm{min}$ respectively in the following investigation. The steady performance of the combined system was evaluated when the engine was operated from $1200 \mathrm{r} / \mathrm{min}$ to $2100 \mathrm{r} / \mathrm{min}$ and over $700 \mathrm{Nm}$. While the ORC system was closed at low engine speed and torque conditions due to the low exhaust energy and small potential for recovering, as well as decrease the negative effects on engine performance.

The exhaust backpressure of the engine with ORC system had notable increase according to Eq.(3). The exhaust resistance increases when the exhaust gas flows through the evaporator, and increases with the increasing of exhaust gas mass flow rate. Therefore, the exhaust backpressure increased with both the engine speed and torque as shown in Figure 8. The maximum backpressure increment is $5.13 \mathrm{kPa}$ at the engine rated operating condition of $2100 \mathrm{r} / \mathrm{min}$ and $1168 \mathrm{~N} \cdot \mathrm{m}$. The raised backpressure had negative impacts on the engine performance, which consequently offset the benefit of the ORC system. The effects were considered in this research, and the improvement of the combined system net output power was analyzed according to Eq.(4). 


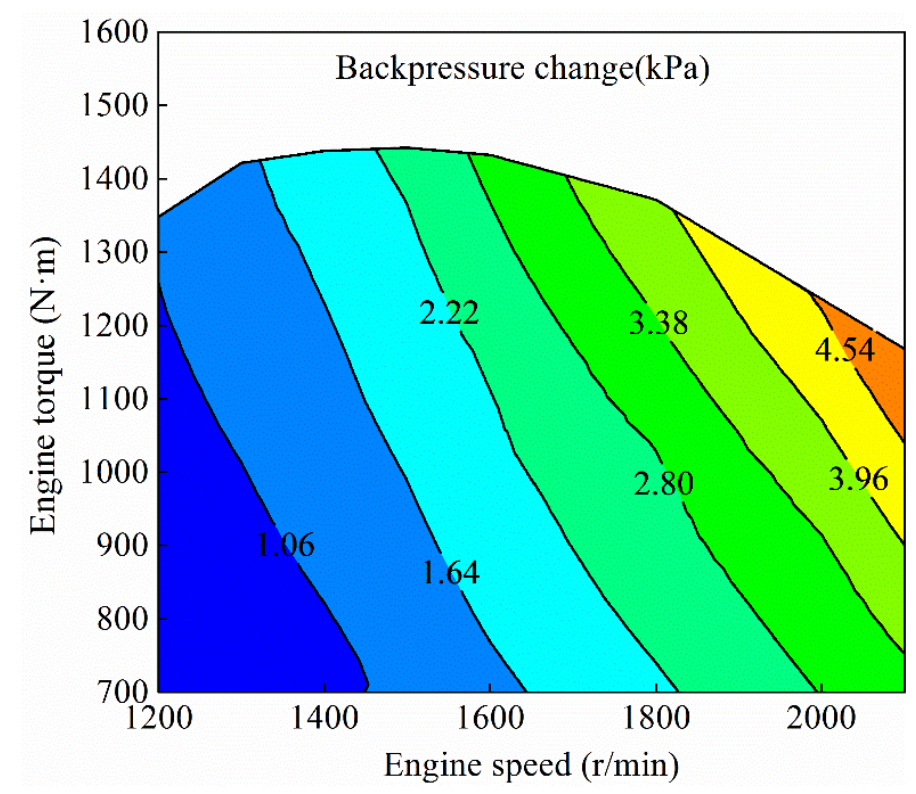

Figure 8 Backpressure change of the engine with ORC system

The net power output improvement of the combined system at different engine speeds and torques was analyzed. Integration of the ORC system increased the power output of the engine as shown in Figure 9. The maximum total power gain is $3.56 \mathrm{~kW}$ when the engine was operated at $2000 \mathrm{r} / \mathrm{min}$ and $1052 \mathrm{Nm}$. The total power gain was negative when the engine operated at low speeds and loads. The energy contained in the exhaust gas was low at these conditions, therefore the power generated by the ORC system was insufficient to cover the power consumption of the cooling system and compensate for engine power loss due to the raised backpressure. The net power output improvement increased with the increasing of engine torque when the engine was operated at low engine speeds, while it firstly increased and then decreased as the engine torque increases when the engine was operated at high engine speeds. The reason is that the exhaust energy increased with both the engine speed and torque according to Figure 2, while the cooling capacity of the cooling system was limited at the constant operating condition, so the expansion ratio and output power of the expander firstly increased and then decreased as the engine power increased. 


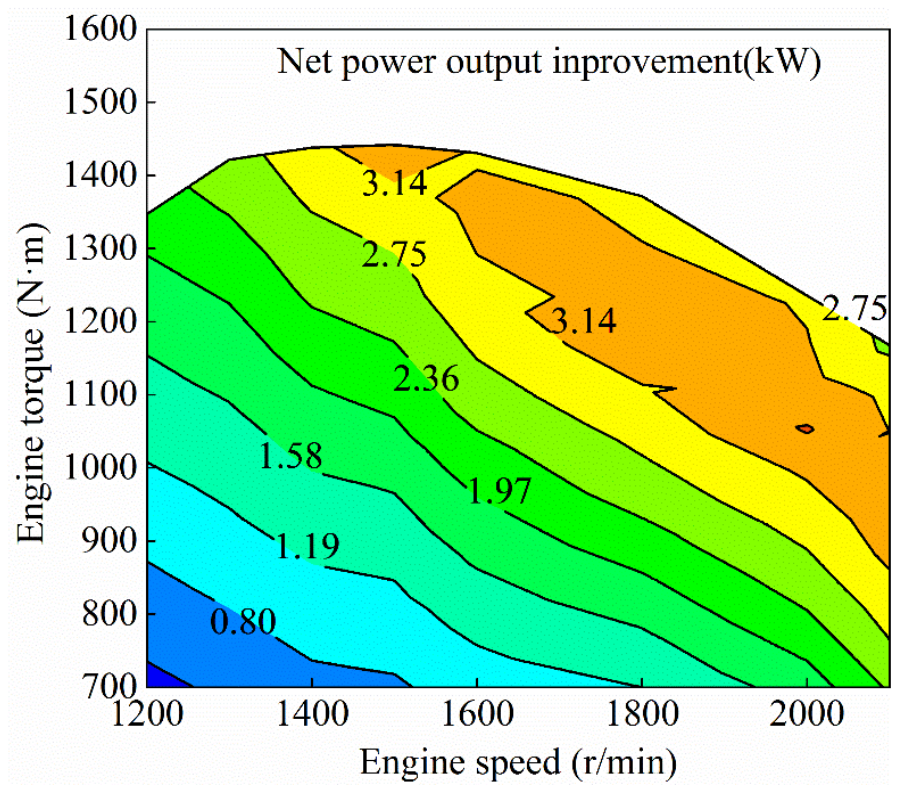

Figure 9 Net power output improvement of the engine with ORC system

The BSFC contours of the engine with or without ORC system at different engine operating conditions are shown in Figure 10. The maximum BSFC of the engine without ORC system is $221.3 \mathrm{~g} /(\mathrm{kW} \cdot \mathrm{h})$ at the speed of $2100 \mathrm{r} / \mathrm{min}$ and the torque of $751 \mathrm{Nm}$, and with ORC system the figure became $216.8 \mathrm{~g} /(\mathrm{kW} \cdot \mathrm{h})$ when the engine operated at $2100 \mathrm{r} / \mathrm{min}$ and $1168 \mathrm{~N} \cdot \mathrm{m}$. The engine BSFC improved considerably by equipping the engine with the ORC system and the maximum BSFC was reduced by $3.6 \mathrm{~g} /(\mathrm{kW} \cdot \mathrm{h})$ when the engine was operated at 2100 $\mathrm{r} / \mathrm{min}$ and $872 \mathrm{~N} \cdot \mathrm{m}$. With the ORC system, the engine can operate with the lower BSFC in a notably larger area, indicating that integration of the ORC system can effectively improve the engine fuel economy.

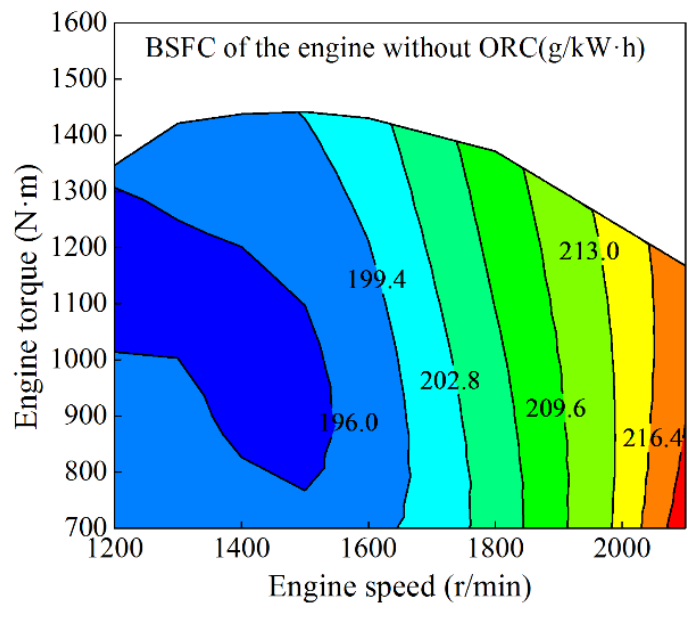

(A)

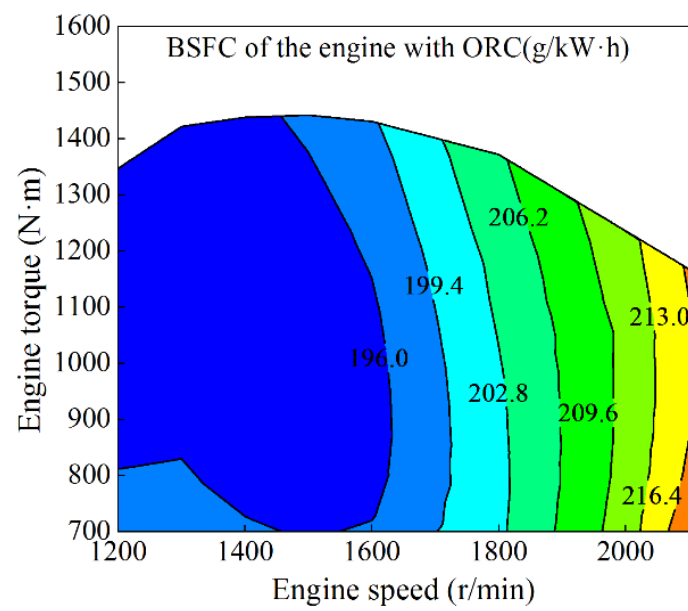

(B)

Figure 10 Variations of BSFC of the engine. (A): The engine without ORC system, and (B): The engine with ORC 
system

\subsection{Performance evaluation with different ambient temperature}

The performance of the combined system at different engine speeds and torques was further evaluated under the ambient temperature of $293 \mathrm{~K}$ and $303 \mathrm{~K}$. The performance of the combined system over this temperature was compared to the case of $298 \mathrm{~K}$.

The net power output improvement for the combined system operating under different ambient temperature is shown in Figure 11. The maximum improvement of the combined system output power can reach to $3.94 \mathrm{~kW}$ and $3.18 \mathrm{~kW}$ at ambient temperatures of $293 \mathrm{~K}$ and $303 \mathrm{~K}$, respectively. Figure 11, together with Figure 9, clearly suggest that increasing ambient temperature has a negative effect on the ORC system performance, and as a result, reduces the combined system performance, but at the same ambient temperature, the figures are similar. The figures also suggest that the system performance varied more with engine speeds and torques under higher ambient temperature. The reason is that the cooling capacity of the cooling system decreases at higher ambient temperature, both the expansion ratio and the output power of the ORC system decrease. Recovering large mass flow rate of the exhaust gas at high engine speed and load conditions can increase the negative effects of the exhaust backpressure on the engine performance, and also decrease the ORC system power output. Therefore, the mass flow rate of the exhaust gas entering the ORC system had to be restricted through controlling the openings of valves ' $a$ ' and ' $b$ ' at high engine speed and torque conditions, especially under high ambient temperatures. 


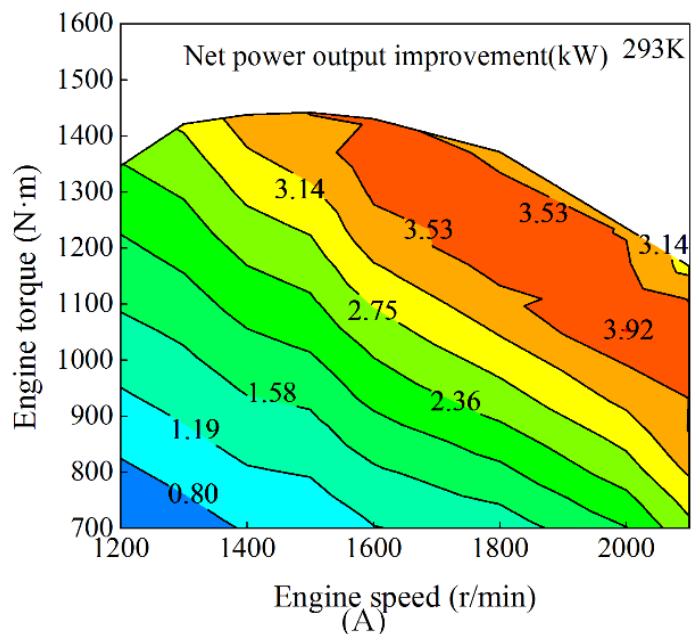

(A)

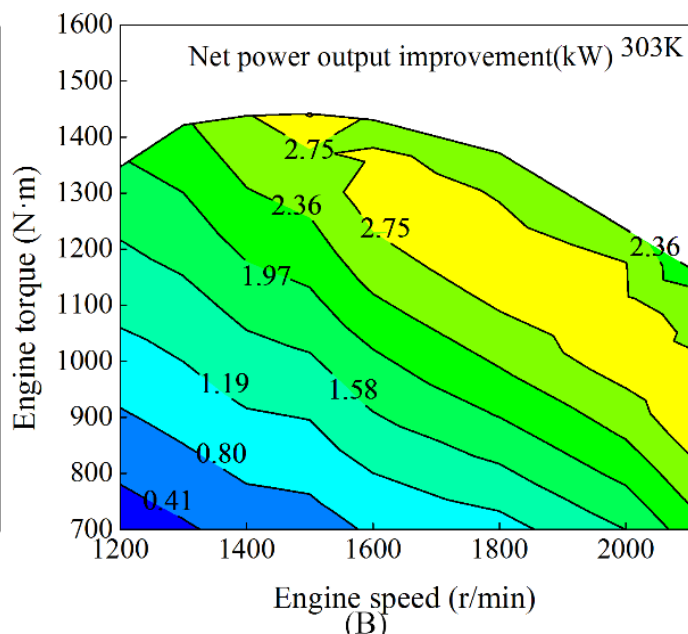

(B)

Figure 11 Variations of net power output improvement. (A): At the ambient temperature of $293 \mathrm{~K}$, and (B): At the ambient temperature of $303 \mathrm{~K}$

Figure 12 describes the BSFC reduction of the combined system at different ambient temperatures. The BSFC reduction of the combined system was calculated by Eq.(6). The maximum BSFC reduction of the combined system was $3.98 \mathrm{~g} /(\mathrm{kW} \cdot \mathrm{h})$ and $3.3 \mathrm{~g} /(\mathrm{kW} \cdot \mathrm{h})$ at ambient temperature of $293 \mathrm{~K}$ and $303 \mathrm{~K}$, respectively. The combined system has higher BSFC reduction and better fuel economy at lower ambient temperature. Therefore, the decrease of ambient temperature has positive effects on the system performance.
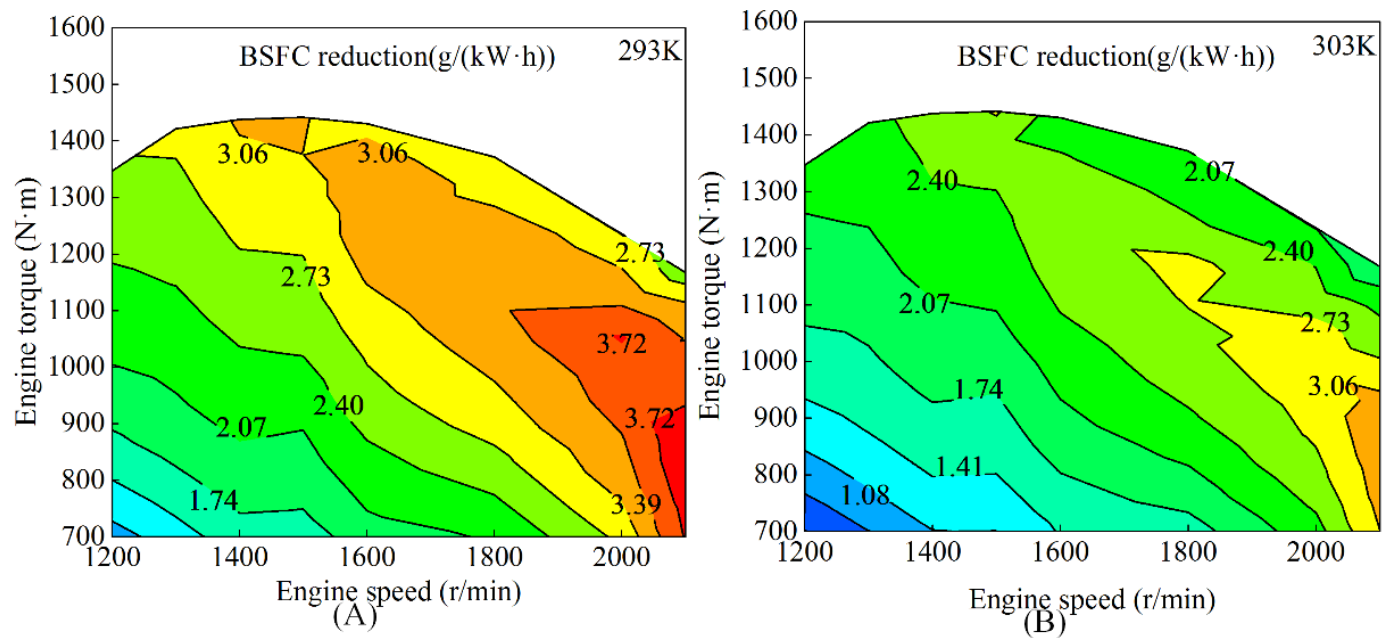

Figure 12 Variations of BSFC reduction. (A): At the ambient temperature of $293 \mathrm{~K}$, and (B): At the ambient temperature of $303 \mathrm{~K}$

\section{Conclusions}

In this paper, an on-board ORC system was used to recover exhaust gas heat from a diesel engine for a heavy 
duty truck. Water and air cooling methods for the ORC system were discussed. The performance of the engine with ORC system at different operating conditions was evaluated. The main conclusions are listed as follows:

(1) Water cooling method is more suitable for the on-board ORC exhaust heat recovery system than air cooling method. The engine with ORC system cooled by water has larger power output and higher thermal efficiency. The operating condition of the water cooling system has significant effects on the benefit of the ORC system, especially the fan speed.

(2) Integration with the ORC system for recovering exhaust heat has effectively improved the engine fuel economy, although has negative effects on engine exhaust backpressure. Decrease of the ambient temperature has positive effects on performance of the combined system. The maximum power output improvement can reach up to $3.94 \mathrm{~kW}$ at ambient temperatures of $293 \mathrm{~K}$.

(3) For the heavy duty diesel engine, the power output improvement firstly increased and then decreased as the engine torque increased at high engine speeds condition, especially under high ambient temperature. Therefore, the available mass flow rate of exhaust gas should be controlled for better performance.

\section{Acknowledgements}

This work was sponsored by the National Natural Science Foundation of China (Grant No.51375048).

\section{Nomenclature}

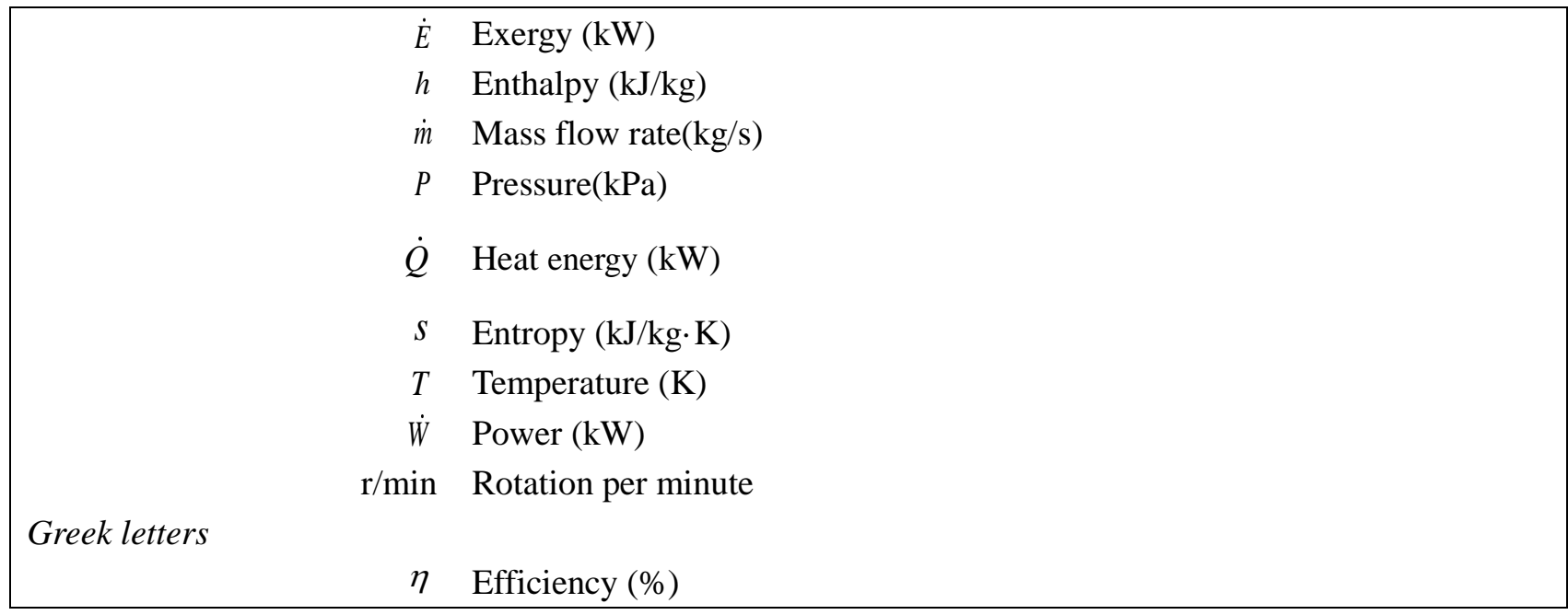




\begin{tabular}{|l|l|}
\hline Subscript & Difference \\
amb & Ambient \\
eva & Evaporator \\
ew & Engine with ORC \\
ewo & Engine without ORC \\
exh & Exhaust gas \\
exp & Expander \\
f & Fan \\
fu & Fuel \\
n & Net power output change \\
pu & Working fluid pump \\
wp & Water pump \\
& \\
BSFC & Brake specific fuel consumption \\
HT & High temperature \\
ORC & Organic Rankine cycle \\
LT & Low temperature \\
\hline
\end{tabular}

\section{References}

[1] DELPHI, Worldwide emissions standard passenger cars and light duty vehicles. delphi.com/emissions-pc.

[2] J. Ko, D. Jin, W. Jang, C.-L. Myung, S. Kwon, S. Park, Comparative investigation of NOx emission characteristics from a Euro 6-compliant diesel passenger car over the NEDC and WLTC at various ambient temperatures, Applied Energy, 187 (2017) 652-662.

[3] H. Teng, G. Regner, C. Cowland, Waste Heat Recovery of Heavy-Duty Diesel Engines by Organic Rankine Cycle Part I: Hybrid Energy System of Diesel and Rankine Engines, SAE, Vol. 2007-01-0537, Detroit, Michigan, 2007.

[4] P. Heidrich, T. Krisch, Assessment of Waste Heat Recovery Options in Passenger Car Applications by Various Rankine Cycles, Heat Transfer Engineering, 36 (2014) 1321-1331.

[5] R. Saidur, M. Rezaei, W.K. Muzammil, M.H. Hassan, S. Paria, M. Hasanuzzaman, Technologies to recover exhaust heat from internal combustion engines, Renewable and Sustainable Energy Reviews, 16 (2012) 5649-5659. [6] J.-H. Meng, X.-D. Wang, W.-H. Chen, Performance investigation and design optimization of a thermoelectric generator applied in automobile exhaust waste heat recovery, Energy Conversion and Management, 120 (2016) 7180 .

[7] Y. Zhang, M. Cleary, X. Wang, N. Kempf, L. Schoensee, J. Yang, G. Joshi, L. Meda, High-temperature and high-power-density nanostructured thermoelectric generator for automotive waste heat recovery, Energy Conversion and Management, 105 (2015) 946-950.

[8] A.M.I. Mamat, A. Romagnoli, R.F. Martinez-Botas, Characterisation of a low pressure turbine for turbocompounding applications in a heavily downsized mild-hybrid gasoline engine, Energy, 64 (2014) 3-16.

[9] R. Zhao, W. Zhuge, Y. Zhang, M. Yang, R. Martinez-Botas, Y. Yin, Study of two-stage turbine characteristic and its influence on turbo-compound engine performance, Energy Conversion and Management, 95 (2015) 414-423. [10] D. Jung, S. Park, K. Min, Selection of appropriate working fluids for Rankine cycles used for recovery of heat from exhaust gases of ICE in heavy-duty series hybrid electric vehicles, Applied Thermal Engineering, 81 (2015) 
338-345.

[11] M. Wang, J. Wang, Y. Zhao, P. Zhao, Y. Dai, Thermodynamic analysis and optimization of a solar-driven regenerative organic Rankine cycle (ORC) based on flat-plate solar collectors, Applied Thermal Engineering, 50 (2013) 816-825.

[12] H. Xi, M.-J. Li, C. Xu, Y.-L. He, Parametric optimization of regenerative organic Rankine cycle (ORC) for low grade waste heat recovery using genetic algorithm, Energy, 58 (2013) 473-482.

[13] J. Song, Y. Song, C.-w. Gu, Thermodynamic analysis and performance optimization of an Organic Rankine Cycle (ORC) waste heat recovery system for marine diesel engines, Energy, 82 (2015) 976-985.

[14] G. Yu, G. Shu, H. Tian, H. Wei, L. Liu, Simulation and thermodynamic analysis of a bottoming Organic Rankine Cycle (ORC) of diesel engine (DE), Energy, 51 (2013) 281-290.

[15] E. Wang, Z. Yu, H. Zhang, F. Yang, A regenerative supercritical-subcritical dual-loop organic Rankine cycle system for energy recovery from the waste heat of internal combustion engines, Applied Energy, 190 (2017) 574590.

[16] H. Tian, L. Liu, G. Shu, H. Wei, X. Liang, Theoretical research on working fluid selection for a hightemperature regenerative transcritical dual-loop engine organic Rankine cycle, Energy Conversion and Management, 86 (2014) 764-773.

[17] L. Guillaume, A. Legros, A. Desideri, V. Lemort, Performance of a radial-inflow turbine integrated in an ORC system and designed for a WHR on truck application: An experimental comparison between R245fa and R1233zd, Applied Energy, 186 (2016) 408-422.

[18] L. Da Lio, G. Manente, A. Lazzaretto, Predicting the optimum design of single stage axial expanders in ORC systems: Is there a single efficiency map for different working fluids?, Applied Energy, 167 (2016) 44-58.

[19] R. Cipollone, D. Di Battista, Sliding vane rotary pump in engine cooling system for automotive sector, Applied Thermal Engineering, 76 (2015) 157-166.

[20] R. Cipollone, D. Di Battista, G. Contaldi, S. Murgia, M. Mauriello, Development of a Sliding Vane Rotary Pump for Engine Cooling, Energy Procedia, 81 (2015) 775-783.

[21] C. Zhang, C. Liu, S. Wang, X. Xu, Q. Li, Thermo-economic comparison of subcritical organic Rankine cycle based on different heat exchanger configurations, Energy, 123 (2017) 728-741.

[22] F. Yang, H. Zhang, Z. Yu, E. Wang, F. Meng, H. Liu, J. Wang, Parametric optimization and heat transfer analysis of a dual loop ORC (organic Rankine cycle) system for CNG engine waste heat recovery, Energy, 118 (2017) 753-775.

[23] T. Li, J. Zhu, W. Fu, K. Hu, Experimental comparison of R245fa and R245fa/R601a for organic Rankine cycle using scroll expander, International Journal of Energy Research, 39 (2015) 202-214.

[24] Y. Wang, X. Liu, X. Ding, Y. Weng, Experimental investigation on the performance of ORC power system using zeotropic mixture R601a/R600a, International Journal of Energy Research, 41 (2017) 673-688.

[25] J. Zhang, Y. Zhou, R. Wang, J. Xu, F. Fang, Modeling and constrained multivariable predictive control for ORC (Organic Rankine Cycle) based waste heat energy conversion systems, Energy, 66 (2014) 128-138.

[26] R.d.O. Neto, C.A.R. Sotomonte, C.J.R. Coronado, M.A.R. Nascimento, Technical and economic analyses of waste heat energy recovery from internal combustion engines by the Organic Rankine Cycle, Energy Conversion and Management, 129 (2016) 168-179.

[27] M.-H. Yang, R.-H. Yeh, Analyzing the optimization of an organic Rankine cycle system for recovering waste heat from a large marine engine containing a cooling water system, Energy Conversion and Management, 88 (2014) 999-1010.

[28] L. Li, Y.T. Ge, X. Luo, S.A. Tassou, Experimental investigations into power generation with low grade waste heat and R245fa Organic Rankine Cycles (ORCs), Applied Thermal Engineering, 115 (2017) 815-824. 
[29] C. Carcasci, R. Ferraro, E. Miliotti, Thermodynamic analysis of an organic Rankine cycle for waste heat recovery from gas turbines, Energy, 65 (2014) 91-100.

[30] R. Shi, T. He, J. Peng, Y. Zhang, W. Zhuge, System design and control for waste heat recovery of automotive engines based on Organic Rankine Cycle, Energy, 102 (2016) 276-286.

[31] V. Grelet, T. Reiche, V. Lemort, M. Nadri, P. Dufour, Transient performance evaluation of waste heat recovery rankine cycle based system for heavy duty trucks, Applied Energy, 165 (2016) 878-892.

[32] S. Lion, C.N. Michos, I. Vlaskos, R. Taccani, A thermodynamic feasibility study of an Organic Rankine Cycle (ORC) for heavy-duty diesel engine waste heat recovery in off-highway applications, International Journal of Energy and Environmental Engineering, (2017).

[33] A. Domingues, H. Santos, M. Costa, Analysis of vehicle exhaust waste heat recovery potential using a Rankine cycle, Energy, 49 (2013) 71-85.

[34] M. Zhao, M. Wei, P. Song, Z. Liu, G. Tian, Performance evaluation of a diesel engine integrated with ORC system, Applied Thermal Engineering, 115 (2017) 221-228.

[35] T. Chen, W. Zhuge, Y. Zhang, L. Zhang, A novel cascade organic Rankine cycle (ORC) system for waste heat recovery of truck diesel engines, Energy Conversion and Management, 138 (2017) 210-223.

[36] T.A. Horst, W. Tegethoff, P. Eilts, J. Koehler, Prediction of dynamic Rankine Cycle waste heat recovery performance and fuel saving potential in passenger car applications considering interactions with vehicles' energy management, Energy Conversion and Management, 78 (2014) 438-451.

[37] V. Dolz, R. Novella, A. García, J. Sánchez, HD Diesel engine equipped with a bottoming Rankine cycle as a waste heat recovery system. Part 1: Study and analysis of the waste heat energy, Applied Thermal Engineering, 36 (2012) 269-278.

[38] D. Di Battista, M. Mauriello, R. Cipollone, Waste heat recovery of an ORC-based power unit in a turbocharged diesel engine propelling a light duty vehicle, Applied Energy, 152 (2015) 109-120.

[39] M. Usman, M. Imran, Y. Yang, B.-S. Park, Impact of organic Rankine cycle system installation on light duty vehicle considering both positive and negative aspects, Energy Conversion and Management, 112 (2016) 382-394.

[40] R. Capata, C. Toro, Feasibility analysis of a small-scale ORC energy recovery system for vehicular application, Energy Conversion and Management, 86 (2014) 1078-1090.

[41] P.J. Yekoladio, T. Bello-Ochende, J.P. Meyer, Thermodynamic analysis and performance optimization of organic rankine cycles for the conversion of low-to-moderate grade geothermal heat, International Journal of Energy Research, 39 (2015) 1256-1271.

[42] S. Song, H. Zhang, R. Zhao, F. Meng, H. Liu, J. Wang, B. Yao, Simulation and Performance Analysis of Organic Rankine Systems for Stationary Compressed Natural Gas Engine, Energies, 10 (2017) 544.

[43] R. Bracco, S. Clemente, D. Micheli, M. Reini, Experimental tests and modelization of a domestic-scale ORC (Organic Rankine Cycle), Energy, 58 (2013) 107-116.

[44] F. Yang, X. Dong, H. Zhang, Z. Wang, K. Yang, J. Zhang, E. Wang, H. Liu, G. Zhao, Performance analysis of waste heat recovery with a dual loop organic Rankine cycle (ORC) system for diesel engine under various operating conditions, Energy Conversion and Management, 80 (2014) 243-255.

[45] M. Wei, P. Song, B. Zhao, L. Shi, Z. Wang, C. Ma, Unsteady flow in the suction process of a scroll expander for an ORC waste heat recovery system, Applied Thermal Engineering, 78 (2015) 460-470.

[46] C. Guo, X. Du, L. Yang, Y. Yang, Organic Rankine cycle for power recovery of exhaust flue gas, Applied Thermal Engineering, 75 (2015) 135-144. 